\title{
CIDADE, FAVELA E DIREITO: COMO PRODUZIMOS O SUBALTERNO
}

\author{
CITY, SLUM AND LAW: HOW WE PRODUCE THE SUBALTERN
}

${ }^{1}$ Yanahê Fendeler Höelz

\section{RESUMO}

O objetivo deste trabalho é traçar um breve panorama das políticas remocionistas destinadas às favelas cariocas e, em especial, à favela da Rocinha, para tentar compreender como o Direito, o Estado e nós, enquanto sociedade, vemos e tratamos esses espaços e as pessoas que neles habitam. A metodologia do trabalho consiste em um levantamento bibliográfico que transita entre áreas das Ciências Sociais e, paralelamente, se inspira nas observações diretas realizadas para uma pesquisa em desenvolvimento no Mestrado. Ao final, serão levantadas reflexões partindo da perspectiva de que os favelados foram produzidos e reproduzidos como uma classe subalterna.

Palavras-chave: Favela; Políticas de remoção; Direito; Rocinha; Classe subalterna

\begin{abstract}
The work's objective is to draw a brief overview of removal policies implemented in slums in Rio de Janeiro and, in particular, in Rocinha slum, trying to understand how the Law, the State and we, as a society, see and treat these spaces and the people who live in them. The work's methodology consists in the literature that passes between Social Sciences areas and, in parallel, is based on direct observations made for research in developing in the master's degree. Finally, reflections will be raised from the perspective that the slum dwellers were produced and reproduced as a subaltern class.
\end{abstract}

Keywords: Slum; Removal Policies; Law; Rocinha; Subaltern Class

Vê agora a ingratidão da humanidade O poder da flor sumítica, amarela que sem brilho vive pela cidade impondo o desabrigo ao nosso povo da Favela (A favela vai abaixo, Sinhô)

\footnotetext{
${ }^{1}$ Mestranda em Direito pela Universidade Federal do Estado do Rio de Janeiro - UNIRIO, Rio de Janeiro (Brasil). E-mail: yanahefendeler@hotmail.com
} 


\section{INTRODUÇÃO}

Quando comecei a minha pesquisa de campo na favela da Rocinha para a dissertação de mestrado, percebi que a favela (pelo menos esta que estou conhecendo) não é um lugar incomum, alienígena, com habitantes de outro planeta. Ao contrário, me espantei com a quantidade de motos, ônibus, comércio e gente que por lá passava, passeava, trabalhava ou simplesmente morava. E por que o espanto?

Esse espanto é fruto de um estigma conferido às favelas pelo imaginário de quem lá nunca habitou. Aos poucos, pude observar que a Rocinha tem seus paradoxos, suas rotinas e seus códigos de conduta como qualquer outro lugar, ou qualquer cidade. E ao contrário do que o senso comum dita, as favelas não são homogêneas, e a Rocinha, ao que me parece, é uma favela heterogênea por excelência.

Nas minhas primeiras incursões ao campo, que procuravam uma aproximação com os policiais da Unidade de Polícia Pacificadora - UPP lá implementada, havia em mim um misto de curiosidade e medo. Curiosidade pelo desconhecido, ou mal conhecido, e medo por uma violência armada, também desconhecida, provocado por um midiático sentimento de insegurança. Não interessa a este trabalho demonstrar resultados das minhas peregrinações à UPP, mas sim, mostrar ao leitor quais foram as reflexões e questionamentos levantados a partir do meu ingresso na favela. Como o Direito, o Estado e nós, enquanto sociedade, vemos e tratamos esses espaços e as pessoas que neles habitam? A Rocinha, enquanto favela, é vista como parte da cidade? Ou ela está sendo usurpada pela cidade?

O objetivo deste trabalho é traçar um breve panorama das políticas remocionistas destinadas às favelas cariocas e, em especial, à favela da Rocinha, para ao final tentar responder minimamente as questões postas acima. A metodologia do trabalho consiste em um levantamento bibliográfico que transita entre áreas das Ciências Sociais e, paralelamente, se inspira nas observações diretas realizadas para a pesquisa em desenvolvimento do Mestrado.

Para tanto, no primeiro capítulo será apresentado um esboço das políticas cariocas relacionadas às favelas e aos seus moradores, desde a sua origem até a produção da cidade olímpica, com especial enfoque às intervenções remocionistas. Em seguida, no segundo capítulo, a favela da Rocinha ganhará destaque com a demonstração da sua resistência à violência citadina. No capítulo final, reflexões serão levantadas a partir da perspectiva de que 
os favelados foram produzidos e reproduzidos como uma classe subalterna e que as favelas apenas são vistas como parte da cidade quando despertam interesse econômico. Uma das consequências desta especulação será o processo de gentrificação.

Cabe, por fim, um esclarecimento: a Rocinha, as favelas, os seus moradores, todos são protagonistas, atores, colaboradores e sujeitos de pesquisas, nunca objeto. Há que se compreender que a favela é um campo vivo, tal como outrora Ezra Park (1973) considerava a cidade, onde se darão relação entre pessoas, não coisas.

\section{O QUE FIZEMOS COM AS FAVELAS}

As primeiras ocupações das encostas dos morros da cidade do Rio de Janeiro foram feitas por imigrantes e pessoas de classe alta que ali construíam as suas residências por acreditarem que os lugares elevados poderiam protegê-las das epidemias. Ao final do século XIX, esses espaços tornaram-se alternativas para moradia de outros grupos sociais: moradores que vinham dos cortiços localizados no centro da cidade (espaços considerados como antro de vagabundagem e de epidemias), escravos recém-libertos e ex-combatentes da Guerra de Canudos que se abrigavam no morro para pressionar o Ministério da Guerra a pagar os seus soldos (VALLADARES, 2000, p. 7; COMPANS, 2007, p. 83).

Os primeiros casebres foram construídos no Morro da Favela ${ }^{2}$, denominado depois de Morro da Providência, e esse território passou a receber atenção após as campanhas para erradicação dos cortiços, que culminou na reforma urbanística do prefeito Pereira Passos (19021906). O Morro da Favela emprestou o seu nome aos demais aglomerados de casebres que foram surgindo e, já no século XX, seu nome já tinha se popularizado. Valladares (2000, p. 78) alerta para a existência de outros morros que também deram origem a esse fenômeno, no entanto, foi o Morro da Favela que entrou para a história. História essa responsável pela gênese da dualidade favela-cidade: o Morro da Favela era visto como o lugar da precariedade física e social, em oposição ao restante da cidade (VALLADARES, 2000, p. 25).

Os primeiros indícios de construção social da favela são encontrados na imprensa do

\footnotetext{
${ }^{2}$ Existem duas explicações para esse nome, segundo Valladares (2000, p. 9): 1) havia nesse morro a mesma vegetação que existia no Morro da Favela de Monte Santo, na Bahia, de onde os ex-combatentes de Canudos vieram; 2) o papel de resistência representado pelo Morro da Favela em Monte Santo ao exército da República sobre Canudos.
} 
começo do século XX, inspirada na obra "Os Sertões" de Euclides da Cunha. As favelas começavam a ser caracterizadas como o reduto da pobreza, onde viviam malandros, vagabundos, capoeiras e, na década de 1920, esses espaços já eram considerados um problema, tão logo políticas públicas começam a aparecer visando sua erradicação (VALLADARES, 2000, p. 11-12; COMPANS, 2007, p. 83).

O discurso de que a favela era um problema de patologia social, defendido por médicos, jornalistas e engenheiros da época, passa a acompanhar o discurso de remodelação da cidade. Nos anos 1926-1927, a cidade recebe uma forte campanha empreendida por Mattos Pimenta contra a favela. Seu principal slogan era considerar a favela como a "lepra da estética". “Outros já haviam denunciado a favela como espaço anti-higiênico, insalubre, local de concentração dos pobres perigosos, área sem lei. Mattos Pimenta retoma esse discurso, mas insiste sobre uma nova bandeira, a estética. Estava nascendo o urbanismo" (VALLADARES, 2000, p. 15).

Em 1930, surge um Plano de Remodelação, Extensão e Embelezamento da cidade do Rio de Janeiro elaborado pelo urbanista francês Alfred Agache, durante a gestão do prefeito Prado Junior. Agache adota posições semelhantes às de Mattos Pimenta, como se percebe em sua definição de favela:

Construídas contra todos os preceitos da higiene, sem canalizações d'agua, sem esgotos, sem serviço de limpeza pública, sem ordem, com material heteróclito, as favelas constituem um perigo permanente de incêndio e infecções epidêmicas para todos os bairros através dos quais se infiltram. A sua lepra suja a vizinhança das praias e os bairros mais graciosamente dotados pela natureza, despe os morros do seu enfeite verdejante e corrói até as margens da mata na encosta das serras (AGACHE, 1930, p. 90 apud VALLADARES, 2000, p. 17).

Os registros sobre as favelas começam a despontar e a discussão se insere na pergunta “o que fazer com esses espaços e com essas pessoas?". Mas esse debate não era sustentado por pesquisas que estamos acostumados a ver hoje no campo das Ciências Sociais. O que se tinha à época era um conjunto de especialistas com variadas formações tecendo leituras da realidade de acordo com o seu campo disciplinar. Em geral, as favelas eram observadas de fora, com um posicionamento condenador (VALLADARES, 2000, p. 18). Nesse cenário, em 1937, surge um Código de Obras com vistas a extinguir as favelas e a formação de "núcleos de habitação de tipo mínimo", conforme disposto em seu capítulo XV intitulado "Extinção das habitações anti- 
higiênicas". Favela, para o então Código, era assim definida:

Art. 349 - A formação de favelas, isto é, de conglomerados de dois ou mais casebres regularmente dispostos ou em desordem, construídos com materiais improvisados e em desacordo com as disposições deste decreto, não será absolutamente permitida.

A favela, uma vez reconhecida, passa a ser considerada um problema. Diversas políticas remocionistas se sucederam, "tendo em comum, além da arbitrariedade e do emprego da violência, o alto valor imobiliário da área ocupada como critério para a escolha daquelas 'marcadas para desaparecer' "' (COMPANS, 2007, p. 83).

Na década de 1940, no primeiro Congresso Brasileiro de Urbanismo, engenheiros e arquitetos demandavam mais informações sobre as favelas. Para Valladares (2000, p. 19), "foi certamente a necessidade de administrar a favela e os seus pobres que despertou o interesse em conhecê-la e conhecê-los mais de perto". Conhecer para controlar. Surgiram, a partir de então, estudos na área médica e de assistência social com o intuito de indicar melhor esses espaços e seus habitantes. Contudo, tais estudos não superaram os clichês destinados às favelas, vinculados a uma imagem de que a pobreza estaria associada a vício, vagabundagem e sujeira.

A imprensa contribuía para confirmar esses clichês e disseminar uma representação social relativa às categorias "favela" e "favelado", que ficou marcada na campanha "Batalha do Rio”, capitaneada pelos jornais O Globo e Correio da Manhã, sob a direção de Carlos Lacerda. O objetivo da ação era apoiar as políticas de remoção esboçadas pelo então prefeito Marechal Ângelo Mendes de Morais (COMPANS, 2007, p. 84). Novas tentativas de mobilizar a opinião pública serão vistas no século seguinte.

O primeiro Censo das Favelas surgiu no final dos anos 40, sob a ânsia de extingui-las ou interromper seu crescimento e, já na década seguinte, foi feito um Censo Demográfico pelo governo federal. Os resultados dos dois censos foram discrepantes ${ }^{3}$. Atribui-se isso à diferença de critérios para a conceituação de favela. O Censo Demográfico do Brasil não contava apenas barracos e seu respectivo número de habitantes. Outros elementos foram introduzidos para a configuração de uma favela, tais como, a condições jurídica da ocupação, os melhoramentos

\footnotetext{
${ }^{3}$ O Censo Demográfico de 1950 teria encontrado 58 favelas, ao passo que o Censo da Prefeitura do Rio teria registrado a existência de 105 aglomerados. O Censo do Rio foi feito dois anos antes que o Censo realizado pelo governo federal, contudo, não há indícios de que nesse período tenha ocorrido remoção de favelas.
} 
públicos, a urbanização, tipos de habitação e proporções mínimas de 50 unidades. Tal multiplicidade de critérios permitiu um avanço no conhecimento desses espaços ${ }^{4}$. (VALLADARES, 2000, p. 24).

A partir de então, as intervenções públicas passaram a ser muito pontuais, mantendo a natureza precária das favelas. Gonçalves (2013, p. 3) aduz que "estabeleceu-se uma política de tolerância extremamente precária e clientelista sem se formular uma resposta jurídica definitiva ao problema das favelas". Com a promulgação da Lei $2.875 / 56$, proibiu-se durante dois anos os despejos contra moradores de favelas situadas na então capital do Brasil. Na medida em que proibia a remoção no final da década de 50, a mesma lei legitimava a remoção nas décadas seguintes, tendo em vista que criou um direito precário, finito.

Com a transferência da capital da República para Brasília, inúmeras mudanças sociopolíticas ocorreram no Rio de Janeiro, dentre as quais se destaca a elaboração da Constituição do Estado da Guanabara. Criou-se, assim, uma estrutura jurídica que legitimava a erradicação das favelas consideradas irrecuperáveis:

Art. 66 - A lei criará um órgão especial incumbido de estudar os problemas de habitação popular, principalmente do tipo "favela", bem como de planejar e executar, em coordenação com os diferentes órgãos, estaduais ou não, suas soluções.

$\S 2^{\circ}$ As favelas serão assistidas e higienizadas, provisoriamente, com a criação de escolas primárias, centros médicos, centros recreativos e de orientação profissional e doméstica. Será estimulada a criação de vilas operárias, com total isenção de impostos, para remoção das favelas irrecuperáveis. [grifo]

Seguiram-se as remoções no governo de Carlos Lacerda, primeiro governador do Estado da Guanabara, e nos seguintes. Decerto que as favelas consideradas "irrecuperáveis" eram aquelas indesejáveis para os lugares mais valorizados do Rio de Janeiro. As políticas remocionistas, "encorajando a construção civil, tolerando as favelas nos subúrbios e erradicando aquelas nos bairros visados pela especulação imobiliária, contribuiu enormemente para o desenvolvimento do mercado imobiliário e aumentou exponencialmente as desigualdades sociais" (GONÇALVES, 2013, p. 9).

Os removidos eram expulsos para "subúrbios longínquos" e, em razão dos novos

\footnotetext{
${ }^{4} \mathrm{Na}$ década de 60, finalmente, surgem as pesquisas das Ciências Sociais nas favelas, sob os preceitos dos métodos de investigação.
} 
custos adquiridos (transporte, condomínio etc.), os favelados retornavam às favelas, tornando inócua essa política de conter a favelização (GONÇALVES, 2013, p. 9).

No período ditatorial, a política de remoção ${ }^{5-6}$ pôde ser feita sem qualquer resistência expressiva, posto que os canais democráticos estavam suprimidos. As associações de moradores das favelas e a Federação das Associações de Favelas do Estado da Guanabara - FAFEG sofriam repressão. Brum (2013, p. 187) transcreve em seu artigo o seguinte relato da FAFEG exposto em uma matéria no Jornal do Brasil, em 31 de novembro de 1968:

Com o trabalho do homem, a cidade cresce, o progresso aproxima-se das áreas onde você habita, crescendo a cobiça desses lugares já valorizados. Embora a lei seja igual para todos, sempre vence o mais forte, e surgem as remoções para lugares longínquos, trazendo vários transtornos para o homem que vive de salário. [grifo] O que será do trabalhador quando a cidade chegar em Vila Aliança, Vila Kennedy e Cidade de Deus? Para onde você vai?

Apesar das expulsões, as favelas cresceram ao longo dos anos e, em 1980, já se consolidavam como um espaço importante de acesso à moradia. Gonçalves (2013, p. 10) observa que a partir desse período houve um certo abandono nas políticas de remoção e isso implicou no reconhecimento tácito das favelas pelo poder público. Esse reconhecimento veio acompanhado da instalação de diversos serviços coletivos nas favelas. Leis e decretos passaram a ser promulgados garantindo as primeiras iniciativas de urbanização, "revelando a lenta e substancial mudança do foco das políticas públicas em relação às favelas" (GONÇALVES, 2013, p. 11). O governo de Leonel Brizola é um exemplo de uma tentativa de redirecionamento das políticas públicas destinadas às favelas e aos favelados. Contudo, observa Gonçalves (2013, p. 14), não houve grandes avanços para o investimento na outorga de títulos formais.

A situação ficou ainda mais complexa com os processos de migração intra-urbana e com a expansão do tráfico de drogas a partir do ingresso da cocaína na cidade. Desde os anos 1980, a favela "virou sinônimo de transgressão à lei e à ordem, espaço que requer incursões policiais, praça de guerra" (SOARES, 2014, p. 9).

\footnotetext{
${ }^{5}$ Segundo a Comissão Estadual da Verdade do Rio de Janeiro - CEV, entre 1962 e 1974, mais de 140.000 pessoas foram removidas de suas casas, especialmente nos bairros como a Lagoa Rodrigo de Freitas e o Leblon. Informações disponíveis em: http://rioonwatch.org.br/?p=18044.

${ }^{6}$ Em 1977, a favela do Vidigal resistiu a uma tentativa de remoção de 320 barracos para a construção de um hotel de luxo. A associação dos moradores conseguiu apoio de juristas renomados, de uma Igreja Católica e até do cantor Ney Matogrosso (MEIRELLES; ATHAYDE, 2014, p. 36-37).
} 
A política de remoção não será amparada pelo processo de redemocratização. A Constituição de 1988 impulsionou um sistema jurídico e político ${ }^{7}$ que visa transformar as favelas em bairro e integrá-las à cidade. Em 1995, sob a administração do prefeito César Maia, foi lançado o projeto Favela-Bairro que consiste em complementar ou construir a estrutura urbana principal (saneamento e democratização de acesso) e oferecer condições ambientais para considerar favela como bairro da cidade. No entanto, há críticas com relação à ausência de participação popular, à dificuldade de compreensão das formas de construção nas favelas, à estagnação da regularização fundiária, à ausência de uma política de segurança conjugada às propostas do projeto, enfim, "o Favela-Bairro, com os seus importantes investimentos em infraestrutura, corre o risco de se tornar uma mera maquiagem urbanística sem a envergadura social que poderia e deveria possuir" (GONÇALVES, 2013, p. 17). Em 2010, surge o Programa Morar Carioca tendo por meta urbanizar todas as favelas até 2020.

Apesar da redemocratização rechaçar a continuidade de políticas remocionistas, nos anos 2000 vimos o retorno (ou permanência) de um discurso conservador e discriminatório em referência às favelas. Compans (2007, p. 84) observa que a disputa por esses espaços se deslocou do campo da política habitacional para o da política ambiental. Isso se deve ao fato de que o Plano Diretor do Rio de Janeiro, instrumento de planejamento municipal de política urbana, admite a exceção ao princípio da não remoção de favelas ${ }^{8:}$

Art. $3^{\circ}$ A política urbana do Município tem por objetivo promover o pleno desenvolvimento das funções sociais da Cidade e da propriedade urbana mediante as seguintes diretrizes:

V - urbanização das favelas, dos loteamentos irregulares e clandestinos de baixa renda, com a implantação de infraestrutura, saneamento básico, equipamentos públicos, áreas de lazer e reflorestamento, aproveitando de todo o potencial turístico, visando à sua integração às áreas formais da Cidade, ressalvadas as situações de risco e de proteção ambiental. [grifo]

\footnotetext{
${ }^{7}$ O Estatuto da Cidade (lei 10.257/2001), por exemplo, regulamenta os arts. 182 e 183 da Constituição Federal relativos à Política Urbana. E o Ministério da Cidades, criado no governo Lula, exercerá papel importante nas políticas de regularização fundiária. Outras leis foram editadas criando ferramentas de planejamento das cidades a partir da regulação de algumas políticas setoriais, dentre elas destacam-se: Lei Federal 11.481/07, que prevê medidas para regularização fundiária de interesse social em bens da União, Lei Federal 11.977/09, que dispõe sobre o Programa Minha Casa Minha Vida e a regularização fundiária de assentamentos localizados em áreas urbanas, Lei Federal 11.445/07, que estabelece diretrizes para o saneamento básico, e lei 12.587/2012, que institui a Política Nacional de Mobilidade Urbana. Veja mais no Relatório para a Habitat III (IPEA, 2016). ${ }^{8}$ Entende-se por favela, de acordo com o referido instrumento, "a área predominantemente habitacional, caracterizada por ocupação clandestina e de baixa renda, precariedade da infraestrutura urbana e de serviços públicos, vias estreitas e alinhamento irregular, ausência de parcelamento formal e vínculos de propriedade e construções não licenciadas, em desacordo com os padrões legais vigentes" (art. 233, $\left.\S 3^{\circ}\right)$.
} 
De acordo com o referido instrumento, se as áreas forem consideradas de risco ou de proteção ambiental, os moradores deverão ser realocados (art. 15, §2 $2^{\circ}$ ). Rose Compans (2007, p. 84) alerta para a difusão da percepção de que a favela é um risco para a coletividade, ora pela possibilidade dos desastres ambientais, ora pelas características da ocupação tomadas como degradação do meio ambiente urbano. Supostas supressões vegetais estariam sendo utilizadas como pretexto para novas remoções. Sob tais alegações, em 2005, o jornal $O$ Globo elaborou uma série de reportagens chamada "Ilegal. E daí?" denunciando a expansão das favelas e incentivando sua remoção.

A primeira reportagem da série denunciava o crescimento da favela da Rocinha, o desrespeito às regras urbanísticas e o não pagamento de impostos. Um ano antes, o Governo do Estado já tinha proposto cercar a favela com a construção de um muro de três metros de altura para impedir sua expansão e desenvolver uma “ocupação social”. A série jornalística seguiu e propiciou um amplo debate com diversos atores sociais, e é exatamente a partir da expressão dessas opiniões que detectamos o incômodo dessas pessoas com relação às favelas. Logo na segunda reportagem da série, o Ministério Público Estadual se pronunciou pela abertura de um inquérito civil a fim de apurar a responsabilidade da Prefeitura pela expansão de cinco favelas, dentre as quais estava a Rocinha. Segundo o promotor da investigação, "todas as construções nas favelas são ilegais e, portanto, sujeitas à demolição" (COMPANS, 2007, p. 89).

Na Câmara Municipal, surgiram projetos de lei propondo mudanças na lei orgânica com o intuito de flexibilizar a remoção das favelas, no entanto, nenhum deles conseguiu assinaturas necessárias para a tramitação. Segundo Compans (2007, p. 91), um desses projetos, de autoria do vereador Carlos Bolsonaro, propunha mudanças na legislação para permitir a remoção independentemente da existência de área de risco. Tal medida deveria ser complementada com o controle de natalidade, de acordo com o vereador.

Esse discurso de degradação ambiental coloca novamente os favelados como um problema, agora como os algozes do desmatamento e da desordem, como se a "cidade" fosse uma protetora exemplar do meio ambiente. “Ou seja, o favelado, que já foi acusado de ser 'avesso à higiene' e sugerido como um delinquente em potencial, agora é anunciado subliminarmente como um predador" (COMPANS, p. 2007, p. 98).

Observa-se que embora a nova égide jurídica não comporte políticas remocionistas, elas ainda ocorrem - como é o caso atual das Olímpiadas 2016 no Rio de Janeiro. Essas 
remoções, por vezes, são amparadas por mudanças feitas na legislação sobre o zoneamento urbano para favorecer determinados interesses ${ }^{9}$. Segundo o jornal El País ${ }^{10, ~ " h o j e, ~ n a ~ m e t a d e ~}$ do segundo mandato do prefeito Eduardo Paes (PMDB), a cifra de pessoas removidas ultrapassa os 70.000 [...]". Na mesma reportagem, o jornal traz o relato do arquiteto Lucas Faulhaber que sugere qual o verdadeiro propósito dos grandes projetos do megaevento:

Tanto os BRTS como o Parque Olímpico ou a revitalização da Zona Portuária são usados, moldados, justamente para viabilizar a retirada de uma favela. Não é que elas precisam sair porque o trajeto passa no meio. Não. O trajeto foi intencionalmente colocado em cima da favela. [...] Os territórios populares sempre foram algo que tem que ser combatido. Desde a época dos cortiços, na era do prefeito Pereira Passos. [grifo] E isso até hoje. A favela é vista como o espaço da criminalidade, da indignidade humana. E algo que tem que ser combatido a partir de argumentos morais, estéticos ou ambientais.

Aliás, nesse particular, cabe ressaltar que o número de pessoas removidas na gestão municipal de Eduardo Paes supera às gestões de Carlos Lacerda (30.000 removidos) e de Pereira Passos (20.000 removidos), relembrados frequentemente por representarem intervenções remocionistas (FAULHABER; AZEVEDO, 2015, p. 36).

Para Gonçalves (2013, p. 21), o Direito não pode se negar a reconhecer a favela como parte integrante da cidade e deve reconhecer as particularidades desse espaço e promover o acesso à moradia e à cidade, "de maneira que o espaço urbano não seja meramente um instrumento para a reprodução do capital”.

Cabe complementar, por fim, que a rasa alegação de que o capitalismo produz pobres e é preciso pensar em um lugar para essa gente apenas enfraquece um debate que é muito mais profundo e complexo que isso - como estou tentando demonstrar. Por muito tempo construímos políticas que visivelmente estigmatizavam espaços e pessoas e ainda hoje vemos o mesmo acontecer sob outra roupagem. Os olhares se despertaram para as favelas quando ali crescia um forte interesse imobiliário; os olhares se despertaram para o favelado quando se percebeu a possibilidade de não ter mais o subalterno por perto; os olhares se despertaram para a violência armada quando a bala começou a atingir o entorno.

A elite se preocupa em manter os seus privilégios. E a classe média se preocupa em

\footnotetext{
${ }^{9}$ É o caso da Lei Complementar 74/2005.

${ }^{10}$ Disponível em: http://brasil.elpais.com/brasil/2015/06/20/politica/1434753946_363539.html.
} 
manter a elite. Como diz Jessé Souza" (2014), a classe média é "uma tropa de choque imbecilizada" que defende os interesses de seus algozes.

\section{A RESISTÊNCIA DA ROCINHA CONTRA A VIOLÊNCIA DA CIDADE}

$\mathrm{Na}$ minha primeira visita à favela da Rocinha, fiquei impressionada com a movimentação constante daquele local. Isso não se deve apenas à quantidade de pessoas que por lá passam, trabalham ou moram, mas pelo intenso tráfego na Estrada da Gávea - estrada que na década de 30 já fez parte do Circuito Automobilístico do Grande Prêmio Cidade do Rio de Janeiro, cuja prova era conhecida como a Corrida das Baratinhas.

A Estrada da Gávea é a rua principal que corta toda a favela da Rocinha. Aquela movimentação de outrora, com os carros automobilísticos, deu espaço ao que hoje chamo de favela viva: muitos mototaxistas, ônibus, carros e motos particulares, vans para transporte de passageiros, Kombi e ônibus escolares, carretas de frete, além do comércio (e parte dele 24 horas), das igrejas, dos turistas, das moradias, da Biblioteca Parque e das dezenas de policiais visivelmente baseados ${ }^{12}$ ao longo da estrada. Mas, na sua origem, esse espaço já foi bem diferente.

A favela da Rocinha, localizada entre bairros de alto poder aquisitivo da Zona Sul da cidade do Rio de Janeiro, era apenas uma fazenda chamada Quebra Cangalha, produtora de cana de açúcar no século XVIII. Os primeiros moradores da Rocinha utilizavam as terras da antiga Fazenda Quebra Cangalha, em torno da década de 20, nos morros da Praia da Gávea. O que antes era engenho de açúcar, acabou se tornando um ambiente de pequenas plantações cultivadas por pessoas que nada tinham - parte delas vinda do êxodo rural resultante da crise do café no início da década de 1930, e outra parte vinda dos operários das indústrias instaladas no Jardim Botânico (SOARES et al., 2009, p. 8).

Uma das versões para o nome "Rocinha" vem da explicação quanto à origem dos produtos comercializados na feira da Praça Santos Dumont, na Gávea, onde os vendedores diziam que tudo vinha da "rocinha do Alto da Gávea".

\footnotetext{
11 Disponível em: http://interessenacional.com/index.php/edicoes-revista/a-cegueira-do-debate-brasileiro-sobre-as-classessociais/.

${ }^{12}$ Lotados.
} 
Em 1927, uma área de aproximadamente $550.000 \mathrm{~m}^{2}$ foi loteada pela Companhia francesa Castro Guidon e Cia e foram abertas algumas ruas a partir da Estrada da Gávea. A comercialização dos lotes viria acontecer apenas em 1933, quando a estrada foi pavimentada. No entanto, a Companhia não atendeu às determinações da legislação urbanística da época e, então, as vendas dos lotes foram interrompidas e a empresa levada à falência. A partir de então, os lotes começaram a ser ocupados esparsamente (EMOP, 2012, p. 24).

As pessoas que vinham de outras regiões para a cidade do Rio em busca de emprego se instalaram inicialmente na Baixada Fluminense, no subúrbio ou em outras favelas; no entanto, a distância do trabalho fez com que muitos deles procurassem a Rocinha (SOARES et $a l ., 2009$, p. 8). Da década de 40 até 60 ocorre um fenômeno de expansão da Zona Sul da cidade e a oferta de empregos passa a atrair uma população mais pobre que acaba construindo suas moradias na Rocinha (EMOP, 2012, p. 27). Com isso, a favela também passou a receber muitos migrantes, principalmente nordestinos, que vinham para a grande cidade em busca de trabalho.

Em 1971, foi inaugurada a Autoestrada Lagoa-Barra, que liga o bairro da Gávea à Barra da Tijuca. Com a construção da estrada e com a abertura Túnel Dois Irmãos, hoje conhecido como Zuzu Angel, o acesso à Rocinha restou reforçado e proporcionou uma intensa circulação de pedestres (EMOP, 2012, p. 28-29). Não é à toa que as áreas da Passarela ${ }^{13}$ e Via Ápia, regiões da Rocinha, concentram hoje um forte comércio e vida noturna na favela.

Em 1970, a Rocinha já tinha alcançado grande extensão e, diante da dificuldade de intervenção remocionista, a favela recebeu os primeiros planos de urbanização. Paralelamente, a deficiência dos serviços públicos crescia e a vulnerabilidade social era intensificada por uma visão discriminatória de que a Rocinha era o lugar de delinquentes (SOARES et al. 2009, p. 9).

No imaginário coletivo, a Rocinha rural, dos anos 30, ocupava uma posição secundária no corpo da cidade, era apenas o seu "quintal distante". A partir da década de 60 "a casa se expande ocupando o quintal", espremendo no fundo o "quartinho". A atenção da opinião pública só passou a se voltar para este "quartinho" a partir da década de 80, quando ele já estava apinhado de gente, ameaçando a segurança da casa (EMOP, 2012, p. 377).

A consolidação da Rocinha ocorre, de fato, na década de 1980. Nessa época, o limite

\footnotetext{
${ }^{13}$ A região é conhecida por esse nome devido à construção de uma passarela, projetada por Oscar Niemeyer, que liga a Rocinha ao seu Complexo Esportivo, interligando os dois lados da Autoestrada Lagoa-Barra. A construção faz parte da primeira fase do Programa de Aceleramento do Crescimento - PAC e foi inaugurada em 2010.
} 
da favela foi se expandindo em direção às encostas da floresta, enquanto permanecia a precariedade dos serviços. A distribuição de água, por exemplo, ficava praticamente restrita às nascentes e poços da localidade. Foi nessa época em que foi formado pela Prefeitura o subbairro do Laboriaux, no qual foram reassentadas famílias removidas para que fosse executada a canalização do valão Campo Esperança - fruto das reivindicações dos moradores (EMOP, 2012, p. 29).

Já na década de 1990, os migrantes não produziam tamanho efeito no crescimento da população da favela, pois os novos moradores surgiam pelo "processo de mobilidade espacial intra-urbana" (SOARES et al., 2009, p. 10). O aspecto de moradias provisórias de outrora, com os barracos de madeira, se misturaram com prédios de vários pavimentos. Muito embora haja um senso comum de que as favelas são homogêneas, ao contrário, dentro delas coexiste uma heterogeneidade - não só no que diz respeito às moradias, mas também quanto aos aspectos culturais, urbanos, econômicos e sociais.

A Rocinha foi transformada em bairro pela Lei 1.995 de 18 de junho de 1993, quando foram definidos seus limites, e foi decretada Área de Especial Interesse Social - AEIS pela Lei 3.351/2001, o que possibilitou a flexibilização de seus parâmetros urbanísticos. Costuma-se chamar a Rocinha de favela-bairro, tendo em vista a permanência das características físicas de favela e de sua identidade cultural. A Rocinha é composta por 25 sub-bairros, que foram nomeados de acordo com a tradição de seus moradores. É considerada uma das maiores favelas da América Latina e é a maior do Brasil, e sua população estimada era, em 2010, de 98.319 habitantes, com o quantitativo de 34.576 domicílios (Censo do EGP-Rio, 2010).

O espaço edificado da Rocinha é complexo e heterogêneo. O uso do espaço compreende a ocupação das áreas de encosta dentro da área de preservação, bem como os pavimentos em todas as áreas indistintamente. A favela subdivide-se em setores os quais expressam a diversidade socioespacial, onde as áreas de difícil acesso (nos becos, por exemplo) são marcadas pela precariedade. Muitas famílias ainda vivem em situações insalubres, expostas ao acúmulo de lixo e em moradias sem ventilação. "Quando chove, as crianças, a caminho da escola, têm dificuldade de achar uma via que não esteja tomada pelo esgoto. Os ratos fazem parte do cotidiano, dão nome às vias, como a do Beco do Rato Molhado" (EMOP, 2012, p. 378). As grandes obras feitas na favela, como o Centro Esportivo implantado pelo Programa de Aceleramento do Crescimento - PAC 1, muitas vezes não são utilizadas pelas crianças 
moradoras das partes altas da favela devido à dificuldade de locomoção.

A partir dos anos 2000, passa a coexistir uma diversidade de atores envolvidos com a gestão do espaço na favela, tais como as ONGs, a iniciativa privada, o Poder Público (em todas as suas esferas), outras instituições e os próprios moradores. Vez ou outra, possíveis remoções são anunciadas (como a movimentação que vimos a partir da série jornalística do jornal $O$ Globo, em 2005), no entanto, o enfrentamento e a resistência a tais políticas é substancialmente forte, até porque a Rocinha se consolidou como uma favela de expressão internacional, o que, em parte, lhe proporciona uma voz mais altiva. Costumo ouvir (dos policiais da UPP) que a Rocinha é uma favela política e que há muitos interesses por lá.

Com o passar dos anos, uma grande diversidade financeira, cultural e comercial foi se consolidando na região. Toda essa heterogeneidade e a paisagem privilegiada que o espaço proporciona fazem da Rocinha um grande ponto turístico e um espaço expressivo na circulação econômica. De acordo com o Censo Empresarial de 2010, a Rocinha contava com aproximadamente 6 mil empreendimentos, a maior parte deles atuando na informalidade. A Rocinha também é a favela campeã em empreendedores, sendo 10,1\% contra 8,5\% no Alemão (MEIRELLES; ATHAYDE, 2014, p. 73).

Mas, repito, a Rocinha é uma favela de paradoxos. A média do poder aquisitivo das famílias oscila de 1 a 2 salários-mínimos. A maior parte (61\%) tem casa própria já quitada e não precisa pagar aluguel. Entre a população ocupada, $81,9 \%$ trabalham no próprio município e, cerca da metade, com carteira assinada. Entretanto, a escolaridade dos chefes de família é considerada baixa, 56\% tem nível fundamental incompleto (EMOP, 2012, p. 377).

Marcelo Neri (2011, p. 65) identifica em sua pesquisa sobre a economia das duas favelas símbolo do Rio de Janeiro (Rocinha e Alemão) que a Rocinha é o inverso do Rio $\left(\right.$ Rocinha $=$ Rio $\left.^{-1}\right)$ :

a) o Rio é quase nordestinamente informal e a Rocinha, apesar de ser a favela mais nordestina do Rio, é fordista formal, isto é, empregos com carteira são mais importantes na Rocinha; b) o Rio é capital de alta escolaridade (a quinta das 27 capitais), já a Rocinha apresenta a menor escolaridade de todas as 34 regiões administrativas da cidade; e c) o Rio é velho e a Rocinha é uma favela jovem. Empiricamente como as favelas são jovens: Rocinha $=$ Jovem $^{2}$.

São mais de 80 anos de existência. E, apesar de sua "riqueza", a Rocinha vive um paradoxo de realidades. "Um dos sub-bairros da Rocinha se chama justamente Faz Depressa, 
refletindo o caráter da construção irregular que deveria ser erguida e ocupada antes da chegada da fiscalização" (SOARES et al., 2009, p. 11).

O descaso estatal ao longo dessas décadas, no que se refere à precariedade na garantia de direitos, resultou na formação de uma favela-bairro com regras, hábitos e mecanismos de administração de conflito próprios, configurando-se como um lugar à margem de quase tudo: dos demais bairros da Zona Sul da cidade, das políticas públicas, do fornecimento de serviços básicos, enfim, à margem da tutela efetiva do Estado. Ao arrepio desses aspectos, a Rocinha, como outras favelas, acabou sendo vista apenas como um lugar sob domínio do tráfico e, em decorrência disso, seria um espaço onde predominam a violência e a criminalidade. Agora, com o forte interesse estatal, o discurso é que esse local precisaria ser ocupado e tomado pelas forças estatais. Aliado a esse interesse, o empresariado surgirá como comparsa do Estado e apoiante da ideia (da UPP).

A Rocinha passa a ser vista como parte da cidade, mas resta saber "de que forma? ", “a quem interessa?". O tempo dirá.

\section{1 Caso Laboriaux}

Nas décadas de 1970 e 1980, os moradores da Rocinha conquistaram alguns avanços bastante expressivos no contexto das favelas cariocas: os primeiros investimentos na urbanização da favela, a não remoção de parte dos moradores para localidades externas à Rocinha e a canalização do Valão Campo Esperança.

Tendo a Prefeitura acatado a manifestação dos moradores com relação à canalização de uma vala de esgoto da favela, os moradores da localidade foram reassentados no Laboriaux, hoje sub-bairro da Rocinha. A urbanização do local foi feita pela Prefeitura para alocar os removidos.

O Laboriaux é uma área privilegiada na Rocinha. Situa-se no topo do morro e tem uma paisagem panorâmica que une a floresta, as praias da Zona Sul, a Pedra da Gávea e a própria Rocinha. É passeio certo dos turistas que visitam a favela. No local também encontramos creche, escola, quadra esportiva, uma bica de água "que só falta 1\% para ser mineral” (como ouvi na região), uma base da UPP no topo do sub-bairro e também tem a Kombi que faz a mobilidade na área, além do mototáxi. 
Em abril de 2010, uma forte chuva caiu sobre o Rio de Janeiro, causando deslizamentos e mortes. A chuva também atingiu as moradias no Laboriaux e provocou duas mortes. Diante da tragédia, o governo não tardou em defender a remoção, muito embora os deslizamentos não tenham ocorrido apenas em favelas. Na semana seguinte, o governo estadual editou o Decreto $n^{\circ} 42.406 / 10$, que institui o Programa Morar Seguro para o reassentamento da população que vive em áreas de risco. Antes, porém, um dia depois da tragédia, o prefeito Eduardo Paes já anunciava a remoção no Laboriaux (BRUM, 2013, p. 195-196).

Segundo o prefeito, a situação de risco estava comprovada pela GEO-Rio (Fundação Instituto de Geotécnica). A Lei Orgânica e o Plano Diretor do Rio de Janeiro vedam a urbanização e regularização fundiária de favelas quando estiver detectada a existência de risco para os moradores. A GEO-Rio é o órgão da Secretaria Municipal de Obras da Prefeitura do Rio de Janeiro responsável pela avaliação dos riscos geológicos e análise da possibilidade de execução de obras de contenção. O problema é que "a detenção de um conhecimento altamente especializado dificulta a contestação de seus pareceres pelas comunidades afetadas, convertendo-se em algo irrefutável e inquestionável" (COMPANS, 2007, p. 88). Mas o Laboriaux questionou. E lutou.

Temendo a interrupção de suas vidas naquele local, os moradores se mobilizaram e logo procuraram algumas instituições para engajamento na luta. Foi então que uma pequena organização local, o Mundo Real, produziu um curta-metragem com o auxílio de alunos de Nova Iorque para divulgar o que estava ocorrendo naquela localidade. Além disso, outros moradores colaboraram com um engenheiro civil para a elaboração de um contra-laudo contestando a validade dos resultados divulgados pela GEO-Rio. O risco de expulsão do local que outrora havia sido "concedido" àqueles moradores, politizou Laboriaux (BAUTÈS et al., 2013, p. 17).

A situação era favorável para a elite carioca que desejava há muito tempo a expulsão dos favelados. A mídia novamente contribuiu para reforçar os anseios pelas políticas remocionistas na medida em que deslegitimava a mobilização, no entanto, os moradores persistiram com a resistência. A ação da comunidade freou a tentativa de remoção e os moradores passaram a organizar mutirões de limpeza. No ano seguinte, a Prefeitura reabriu a escola que tinha sido fechada à época e construiu muros de contenção. Em 2013, a rua principal do Laboriaux foi asfaltada (BAUTÈS et al., 2013, p. 17-18). 
Embora os moradores do Laboriaux tenham vencido a luta contra a remoção amparada pela GEO-Rio, "nada impede que ela se materialize nos tratores da especulação imobiliária" (BAUTÈS et al., 2013, p. 18). Esse talvez seja o grande desafio da Rocinha hoje: exigir melhorias preservando o seu espaço, a sua história e os seus moradores diante do processo de gentrificação ${ }^{14}$ - que é uma forma de remoção cruel, velada e violenta. “E 'gentrificar' ou ser 'gentrificado' não é uma escolha como nos tentam colocar. Faz parte de uma política" (FAULHABER; AZEVEDO, 2015, p. 19).

\section{3 “A SÍNDROME DE COLOMBO"}

Compreender a relação que os moradores das favelas têm com o seu lugar é de extrema importância para se pensar em qualquer política nesses espaços. Quando o direito é produzido de forma impositiva, não há compreensão do direito dessas localidades. A realidade é muito maior do que os códigos e as bibliotecas podem alcançar.

A cidade trata os favelados da mesma forma que os europeus trataram os índios (e nós ainda os tratamos): se apropriando deles. Talvez o problema citadino consista, como o cineasta Spike Lee ${ }^{15}$ falou em entrevista, na síndrome de Cristóvão Colombo: "[...] você não pode descobrir esse lugar. Nós já estávamos aqui. Você simplesmente não pode vir e se apropriar”.

A dificuldade que temos de integrar a favela à cidade, considerando a preservação da história e cultura do lugar, é devido à alienação dos que vêm de fora, dos que vêm pensando em se apropriar daquelas pessoas e dos espaços onde vivem, dos que não enxergam o pertencimento dos moradores à favela. A "nossa" vida urbana não entende isso, não entende as relações de vizinhança, não entende os vínculos afetivos com a terra (lugar de onde vieram ou onde fizeram suas vidas). Parece um discurso romantizado, mas isso é porque abominamos as favelas e os favelados ao longo de décadas, o que obstruiu a nossa capacidade de visão.

\footnotetext{
14 “"...] esse processo de maior atenção (das autoridades e do mercado imobiliário) de áreas da cidade por causa dos 'Grandes Eventos' tem levado ao fenômeno da gentrificação, ou seja, a ocupação por classes de maior poder aquisitivo de uma área previamente ocupada por classes mais pobres, num processo de valorização econômica da área e transformações físicas e sociais" (HAMNETT, 1991, p. 178, apud BRUM, 2013, p. 197).

${ }^{15}$ Disponível em: http://www.diariodocentrodomundo.com.br/o-que-e-gentrificacao-e-por-que-ela-gerando-tanto-barulho-nobrasil/.
} 
Pensar como Viveiros de Castro $^{16}$ (2016, passim) pode ajudar a iluminar nossas vistas embaçadas. Tratamos, pois, os favelados como indígenas, como aqueles originados da terra em que vivem, como uma comunidade ligada ao espaço, como integrantes de um povo:

Ser indígena é ter como referência primordial a relação com a terra em que nasceu ou onde se estabeleceu para fazer sua vida, seja ela uma aldeia na floresta, um vilarejo no sertão, uma comunidade de beira-rio ou uma favela nas periferias metropolitanas. [grifo] É ser parte de uma comunidade ligada a um lugar específico, ou seja, é integrar um 'povo'.

Tirar o lugar dos moradores de favela, enquanto indígenas, é separar as pessoas dos seus corpos, é criar uma população administrada - conforme argumenta Viveiros de Castro. Isso não significa que a favela não quer ter acesso aos serviços fornecidos pelo Estado, que ela não quer ter acesso aos direitos e garantias respaldados pelo Estado, ou que ela não quer fazer parte da cidade integrada ao Estado. Pelo contrário, isso significa que a favela quer administrar junto ao Estado, quer gerir seu espaço de forma participativa com o Estado, mas ela não quer ser controlada por um Estado que não a reconhece.

Pertencer à terra, em lugar de ser proprietário dela, é o que define o indígena. E nesse sentido, muitos povos e comunidades no Brasil, além dos índios, podem se dizer, porque se sentem, indígenas muito mais que cidadãos. Não se reconhecem no Estado, não se sentem representados por um Estado dominado por uma casta de poderosos e de seus mamulengos e jagunços aboletados no Congresso Nacional e demais instâncias dos Três Poderes (CASTRO, 2016).

O fato que pretendo chamar atenção aqui é que existe uma parcela da população brasileira invisível ou, quando visível, mal compreendida e explorada. Os favelados viveram a amargura do abandono durante muito tempo, foram estigmatizados, excluídos e criminalizados, consolidando uma parte do que Jessé Souza (2014, passim) chama de ralé brasileira, é dizer, "os muito precarizados socialmente", uma classe "condenada a exercer todos os trabalhos mais duros, humilhantes, sujos, pesados e perigosos”. Essa classe é explorada não apenas pela elite, mas pela verdadeira classe média, que vai fornecer aos seus explorados o que for suficiente para manter eternamente a condição subalterna.

Decerto que parte dos moradores das favelas, e a Rocinha é um exemplo disso, ascenderam financeiramente e ingressaram no mercado de consumo: como se diz

\footnotetext{
${ }^{16}$ Disponível em: http://www.ihu.unisinos.br/noticias/554056-povos-indigenas-os-involuntarios-da-patria.
} 
popularmente/estatisticamente, ascenderam à classe $C^{17}$. Ledo engano, no entanto, é pensar que esse contingente faz parte da classe média. Nem nova, nem velha. Não se verifica nessa "nova" classe privilégio algum, pelo contrário, ela é formada por “batalhadores", como sustenta Jessé Souza (2011, p. 35-36).

Os "batalhadores", nome que é uma homenagem a essa classe que se reinventou sozinha sob as piores condições, se assemelham muito mais a uma classe trabalhadora precarizada, típica do contexto social do pós-fordismo, sem direitos e garantias sociais, que trabalha de 10 a 14 horas ao dia, estuda à noite e faz bicos nos fins de semana. Seu potencial de consumo pressupõe extraordinário esforço pessoal, sacrifício familiar de todo tipo, além de todo tipo de sofrimentos e dores silenciadas pelo discurso triunfalista dominante.

Os batalhadores também são precarizados socialmente. Trata-se de uma massa de trabalhadores com uma herança social, uma história com muitas limitações e restrições, sobre a qual também recaem preconceitos - reforçados no caso de favelados. Os batalhadores não têm o privilégio do tempo livre que permite a apropriação do capital cultural - detido e retido pela classe média. Esse capital cultural é constituído tanto pelas "pré-condições afetivas e psíquicas para o aprendizado; quanto pelo aprendizado em si do conhecimento julgado útil" (SOUZA, 2014, passim). O que diferencia a ralé dos batalhadores é que estes últimos "conseguiram maiores recursos e possibilidade de ascensão social", ao passo que a ralé consegue apenas pensar em vender o almoço para comprar a janta, sem qualquer expectativa de/no futuro.

Na Rocinha, vejo a ralé e os batalhadores, ambos percebidos como subalternos à cidade e às pessoas da cidade. Mas vejo também resistência aos Colombos que às vezes chegam para se apropriar da terra e dos indígenas.

\section{CONSIDERAÇÕES FINAIS}

Embora haja muitas pesquisas publicadas na área das Ciências Sociais evidenciando como as favelas foram tratadas ao longo das décadas, predomina "aqui fora" um vergonhoso senso comum, ainda que velado, que esses espaços são "um câncer" para a sociedade. Dependendo do momento histórico, as favelas são caracterizadas como um problema sanitário, moral, estético, social, ambiental ou de segurança pública. E problema entendido ora como algo

\footnotetext{
${ }^{17}$ Em 2013, a maior parte dos moradores das favelas já pertencia à chamada classe C. Segundo Meirelles e Athayde (2014, p. 28), a parcela de famílias faveladas nessa classe é maior do que a do Brasil como um todo: $65 \%$ a $54 \%$.
} 
pejorativo, ora como uma questão a ser debatida por quem não está implicado nele. Ao fim e ao cabo, os favelados ainda são vistos como subalternos.

Os favelados foram (considerados) sempre os inferiores, as favelas foram sempre espaços rejeitados. Já que o discurso das políticas remocionistas de outrora não cabe formalmente no sistema jurídico, hoje a moda é encobrir o discurso da remoção sob a justificação benevolente de proteção ao morador em área de risco e de preservação ambiental como iria acontecer no caso narrado no Laboriaux, na Rocinha, e só não foi levado ao fim porque houve mobilização suficiente para, entre outras medidas, elaborar um contra-laudo.

Não se trata aqui de uma apologia ao dano ambiental, tampouco à construção de moradias em lugares impróprios, arriscados; no entanto, há que se entender a herança social dessas pessoas que construíram moradias precarizadas e dar a elas um tratamento sensível e adequado. Mediar o conflito e potencializar a participação do favelado na gestão do espaço é o caminho menos injusto para aquele que durante décadas foi injustiçado. Mas para isso, a sociedade, em especial a classe média, precisaria se dar conta do quão exploradora é, do quão preconceituosa se consolidou. Integrar a favela à cidade não significa tomá-la para si.

Podem me dizer que o apartamento do Parque Carioca é maravilhoso. Moradia não é quatro paredes, mas a história, o vínculo da comunidade, da identidade de cada um de nós com o nosso lugar. Nós vamos resistir até o fim. (Altair Guimarães, presidente da Associação de Moradores, Pescadores e Amigos da Vila Autódromo, apud FAULHABER; AZEVEDO, 2015, p. 94).

\section{REFERÊNCIAS BIBLIOGRÁFICAS}

AGACHE, Alfred. Cidade do Rio de Janeiro: extensão - remodelação - embelezamento. Rio de Janeiro, Prefeitura do Distrito Federal. 1930.

BAUTÈS, Nicolas; FERNANDES, Lenise Lima; BURGOS, Marcos David. Entre confrontos e desafios na construção da legitimidade popular: algumas perspectivas sobre os movimentos de resistências em favelas do Rio de Janeiro. Libertas, v. 13, n. 2, 2013. Disponível em: https://libertas.ufjf.emnuvens.com.br/libertas/article/view/2752/2238. Acesso em: 26 jun. 2016.

BETIM, Felipe. Remoções na Vila Autódromo expõem o lado B das Olimpíadas do Rio. EI País, Rio de Janeiro, 05 ago. 2015. Olimpíadas Rio 2016. Disponível em: http://brasil.elpais.com/brasil/2015/06/20/politica/1434753946_363539.html. Acesso em: 24 jun. 2016. 
BRUM, Mario. Favelas e remocionismo ontem e hoje: da Ditadura de 1964 aos Grandes Eventos. O Social em Questão, ano XVI, n. 29, 2013.

CASTRO, Eduardo Viveiros de. Os involuntários da pátria. Aula Pública, Cinelândia, 20 de abr. 2016. Disponível em: http://www.ihu.unisinos.br/noticias/554056-povos-indigenas-osinvoluntarios-da-patria.

COMPANS, Rose. A cidade contra a favela: a nova ameaça ambiental. Revista Brasileira de Estudos Urbanos e Regionais, v. 9, n. 1, maio 2007.

EGP-RIO. Censo favelas PAC. Disponível em: http://arquivos.proderj.rj.gov.br/egprio_imagens/Uploads/Apres_censo.pdf. 2010.

EMOP. Relatório de Diagnóstico Urbano, Ambiental e Social. Projeto de Orçamentação para melhorias urbanas habitacionais PAC 2 no Complexo da Rocinha. 2012. Disponível em: http://www.emop.rj.gov.br/wp-content/uploads/2014/06/Diagnostico-Rocinha.pdf.

ESTADO DA GUANABARA. Constituição do Estado da Guanabara. Estado da Guanabara, 27 de março de 1966. Disponível em: http://download.rj.gov.br/documentos/10112/1297190/DLFE-56231.pdf/REVISTA11717.pdf. Acesso em: 23 jun. 2016.

FAULHABER, Lucas; AZEVEDO, Lena. SMH 2016: Remoções no Rio de Janeiro Olímpico. Rio de Janeiro: Mórula, 2015. 123p.

GONÇALVES, Rafael Soares. A política, o direito e as favelas do Rio de Janeiro: um breve olhar histórico. URBANA: Revista Eletrônica do Centro Interdisciplinar de Estudos sobre a Cidade, Campinas, SP, v. 1, n. 1, abr. 2013. ISSN 1982-0569. Disponível em: <http://periodicos.sbu.unicamp.br/ojs/index.php/urbana/article/view/8635115>. Acesso em: 23 jun. 2016.

IPEA. Relatório brasileiro para o Habitat III. Brasília: ConCidades, IPEA, 2016.

MEIRELLES, Renato; ATHAYDE, Celso. Um país chamado Favela: a maior pesquisa já feita sobre a favela brasileira. São Paulo: Editora Gente, 2014.

NERI, Marcelo. UPP ${ }^{2}$ e a economia da Rocinha e do Alemão. Conjuntura Econômica, p. 62-65, dez. 2011. Disponível em: http://www.cps.fgv.br/cps/bd/clippings/nc2116a.pdf. Acesso em 27 mar. 2016.

PARK, Robert Ezra. A cidade: sugestões para a investigação do comportamento humano no meio urbano. In: VELHO, Otávio (Org.). O Fenômeno Urbano. Rio de Janeiro: Zahar Editores, 1973. p. 26-67. 
PREFEITURA DO DISTRITO FEDERAL. Código de obras do Distrito Federal. Decreto n. 6.000 de $1^{\circ}$ de julho de 1937. Rio de Janeiro, Prefeitura do Distrito Federal, 1937. Disponível em: http://www.rio.rj.gov.br/web/arquivogeral/raridades. Acesso em: 23 jun. 2016.

PREFEITURA DO RIO DE JANEIRO. Lei Complementar 111, de $1^{\circ}$ de fevereiro de 2011. Dispõe sobre a Política Urbana e Ambiental do Município, institui o Plano Diretor de Desenvolvimento Urbano Sustentável do Município do Rio de Janeiro e dá outras providências. Diário Oficial do Rio de Janeiro, 13 abr. 2011.

SOARES, Luiz Eduardo. Prefácio. In: MEIRELLES, Renato; ATHAYDE, Celso. Um país chamado Favela: a maior pesquisa já feita sobre a favela brasileira. São Paulo: Editora Gente, 2014.

SOARES, Priscila; OLIVEIRA, Fabio Bruno de; SAMPAIO, Milena. Rocinha, um breve histórico no tempo: análise dos processos de formação e transformação do bairro. In: XIII Encontro da Associação Nacional de Pós-Graduação e Pesquisa em Planejamento Urbano e Regional, Florianópolis, 25-29 maio. 2009.

SOUZA, Jessé. A cegueira do debate brasileiro sobre as classes sociais. Revista Interesse Nacional, ano 7, n. 27, out./dez. 2014. Disponível em: http://interessenacional.com/index.php/edicoes-revista/a-cegueira-do-debate-brasileiro-sobreas-classes-sociais/. Acesso em: 27 jun. 2016.

. A parte de baixo da sociedade brasileira. Revista Interesse Nacional, ano 4, n. 14, jul./set. 2011. Disponível em: http://interessenacional.com/index.php/edicoes-revista/a-partede-baixo-da-sociedade-brasileira/. Acesso em: 27 jun. 2016.

VALLADARES, Licia. A gênese da favela carioca. A produção anterior às ciências sociais. Revista Brasileira de Ciências Sociais, v. 15, n. 44, out. 2000. 